\title{
Article
}

\section{Team Coordination in High-Risk Circus Acrobatics}

Filho, Edson and Rettig, Jean

Available at http://clok.uclan.ac.uk/19806/

Filho, Edson ORCID: 0000-0002-8548-4651 and Rettig, Jean (2018) Team Coordination in High-Risk Circus Acrobatics. Interaction Studies, 19 (3). ISSN 1572-0373

It is advisable to refer to the publisher's version if you intend to cite from the work.

For more information about UCLan's research in this area go to

http://www.uclan.ac.uk/researchgroups/ and search for < name of research Group>.

For information about Research generally at UCLan please go to

http://www.uclan.ac.uk/research/

All outputs in CLoK are protected by Intellectual Property Rights law, including Copyright law. Copyright, IPR and Moral Rights for the works on this site are retained by the individual authors and/or other copyright owners. Terms and conditions for use of this material are defined in the policies page.

\section{CLoK}

Central Lancashire online Knowledge www.clok.uclan.ac.uk

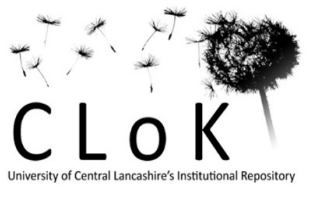




\section{Team Coordination in High-Risk Circus Acrobatics}

\section{$\underline{\text { Abstract }}$}

To advance understanding of the mechanisms allowing for team coordination (TC) in complex motor actions, we conducted a qualitative study with eight elite hand-to-hand circus acrobats. Data collection consisted of field observations, an open-ended interview with the participants' head coach, and focus group interviews with all acrobats. Data analysis yielded three higher order themes: TC, collective efficacy (CE), and TC-CE linkage. Teammates' shared and complementary mental models, as well as implicit and explicit communication dynamics, emerged as formative sub-themes of TC; self- and other's-efficacy emerged as reflective sub-themes of $\mathrm{CE}$. Our findings also suggest that $\mathrm{TC}$ is likely inter-related to $\mathrm{CE}$ in a systemic fashion. Practitioners should encourage the development of both shared and complementary models of thinking, while promoting verbal and non-verbal communication skills. Finally, increasing teammates' confidence in themselves and in their teammates can help in the development of CE as well as the enhancement of TC.

Keywords: team coordination; shared mental models; group dynamics; collective efficacy; dyadic teams.

\section{Author:}

Edson Filho

University of Central Lancashire

Email: EFilho@uclan.ac.uk

Address: School of Psychology, Darwin Building DB114, Preston, Lancashire PR1 2HE United Kingdom

\section{Author:}

Jean Rettig

Florida State University

Email: jdr08e@fsu.edu

Address: 185 Early's Mill Road, Hummelstown, Pennsylvania, 17036, USA

\section{Biographical note:}

Dr. Filho is currently a Lecturer in Sport and Exercise Psychology at the University of Central Lancashire. His research agenda revolves around expert performance, team dynamics, and neuroscience.

Dr. Rettig received a doctoral degree in Higher Education from FSU and is currently an adjunct faculty at FSU. Her research interests include higher education, student-athlete engagement, and sport psychology. 
Running head: TEAM COORDINATION IN HAND-TO-HAND ACROBATICS

\section{Team Coordination in High-Risk Circus Acrobatics}

43 Whether the unit of analysis is an atom, the human brain, or a sports team, scholars

44 concur that coordination occurs when two or more agents are in the "right place", at the

45 "right time", doing the (most likely or expected) "right thing" (see Eccles, 2010; Kelso,

46 2012; Wood, 2003). Put plainly, coordination pertains to "space-time-action" synchrony

47 (see Eccles, 2010). Despite interdisciplinary agreement on the operational definition of

48 coordination, the underlying mechanisms that allow for "space-time-action" congruence

49 remain unclear at least within the Sport, Exercise and Performance Psychology literature

50 (see Carron \& Spink, 1993; Filho, Tenenbaum, \& Yang, 2015a; Klimoski \& Mohammed,

51 1994; Peterson, Mitchell, Thompson, \& Burr, 2000; Reimer, Park, \& Hinsz, 2006). This

52 ambivalence might arise from the fact that team coordination (TC) is a multi-layered

53 process that requires in-depth qualitative exploration. To put it another way, although

54 scholars agree on the definition of TC, the underlying mechanisms (formative and/or

55 reflective indicators) that lead to TC remain unclear. This might be due to the fact that team

56 processes, such as cohesion and collective efficacy, are intertwined, akin to the notion of

57 reciprocal determinism or many-to-many basis relationship interactions in applied

58 psychology (see Bandura, 1997; Cacioppo, Tassinary, \& Berntson, 2007).

59 Within this complex research scenario, we focused our "exploration ground" on

60 acrobatic dyadic teams, wherein "space-time-action" congruence is essential for optimal

61 performance and safety (Ménard \& Hallé, 2014). To this extent, research on team processes

62 has relied on nomothetic methodologies guided by "regression to the mean" arguments (see

63 Hiller, DeChurch, Murase, \& Doty, 2011). Accordingly, it is paramount to advance

64 idiographic research aimed at eliciting knowledge from skilled individuals involved in 
Running head: TEAM COORDINATION IN HAND-TO-HAND ACROBATICS

65 interactive teams (Filho \& Rettig, 2016). Our initial theoretical map was the Conceptual

66 Framework of Coordination in Teams (see Eccles \& Tenenbaum, 2004), which has

67 informed research on TC in Sport, Exercise and Performance Psychology in recent years

68 (see Collins \& Durand-Bush, 2015; Filho \& Tenenbaum, 2012).

69 Conceptual Framework of Coordination in Teams

70 The main tenet of the Conceptual Framework of Coordination in Teams is that TC

71 is dependent on shared mental models (SMM). SMM has been defined as "teammates'

72 shared understandings about team tasks, task context and strategies, team interaction

73 patterns, and teammates' traits” (Xinwen, Erping, Ying, Dafei, \& Jing, 2006, p. 598). In

74 this context, Eccles and Tenenbaum (2004) purport that TC is dependent on SMM such that

75 an increase in the quality and quantity of shared knowledge within a team facilitates

76 division of labor among teammates, which in turn promotes team performance. In

77 discussing coordination in teams, Eccles and Tenenbaum (2004) also noted that SMM, and

78 TC in turn, can be improved through verbal and non-verbal communication prior to (i.e.,

79 pre-process coordination), during (i.e., in-process coordination), or after team actions (i.e.,

80 post-process coordination).

81 Although previous research supports the thesis that TC is linked to SMM and

82 communication processes (see Gershgoren, Filho, Tenenbaum, \& Schinke, 2013; Giske,

83 Rodahl, \& Høigaard, 2015; Mathieu, Heffner, Goodwin, Salas, \& Cannon-Bowers, 2000;

84 Reimer et al., 2006), there remains a need to clarify the unique nomological roots of TC.

85 Some scholars have contended that a view of TC based on SMM is somewhat limited, as it

86 does not account for idiosyncratic knowledge within the team (Arrow, Poole, Henry,

87 Wheelan, \& Moreland, 2004; Mohammed, Ferzandi, \& Hamilton, 2010). In other words, 
88 "group thinking" and thus TC breakdowns are more likely to happen if divergent thinking

89 patterns are not present in working teams (Filho \& Tenenbaum, 2012; Salas, Rosen, Burke,

90 Goodwin, \& Fiore, 2006).

91 The discussion of TC extends beyond the socio-cognitive approach, and has also

92 been examined within a dynamic systems view. In particular, some scholars have posited

93 that TC might not rely primarily on SMM but rather on "affordances", which are unique to

94 the teammates performing a given task within a specific context (see Marsh, Richardson, \&

95 Schmidt, 2009; Silva, Garganta, Araújo, Davids, \& Aguiar, 2013; Vilar, Araújo, Davids, \&

96 Button, 2012). In this regard, Silva et al. (2013) have noted that it is the ability to perceive

97 "collective affordances" - or the dynamic relationships among teammates, their opponents,

98 and environmental pressures - that allows teammates to establish coordination in

99 interactive team tasks. Also noteworthy, within this dynamic systems view, there are

100 scholars who compare TC to "chemical reactions" or "team chemistry" (see DeLong et al.,

101 2011; Gershgoren et al., 2016), thus adding further nomological confusion to research on

102 group dynamics in applied psychology (see Filho, 2015).

\section{The Present Study}

104 The unique nomological roots of TC need to be clarified if applied psychologists

105 are to develop a parsimonious, evidence-based understanding of how myriad team

106 processes are inter-related within a systemic (i.e., reciprocal determinism; Bandura, 1997;

107 many-to-many basis relationship; see Cacioppo et al., 2007) and integrated view of team

108 dynamics (Filho et al., 2015a; Klimoski \& Mohammed, 1994; Mohammed et al., 2010;

109 Short, Sullivan, \& Feltz, 2005). Accordingly, to deepen the understanding of TC, we

110 conducted an exploratory focus group study with professional hand-to-hand circus acrobats 
111 at a world-leading circus school. Our purpose was to explore circus artists' understanding

112 of how TC is developed in dyadic hand-to-hand acts. Specifically, our research question

113 was: "How is team coordination developed between elite flyers and catchers in high-risk

114 circus acts?" No hypotheses or propositions were formulated a priori, as the study was

115 framed within a constructivist stance in general (Mills, Bonner, \& Francis, 2006; Patton,

116 2002). The participants were invited to construct (and re-construct) their understanding of

117 TC in common hand-to-hand acts during a series of interviews.

\section{Method}

\section{Participants}

120 We purposefully recruited high-skilled hand-to-hand acrobats from a circus school

121 in northeast Canada. The school is geared towards high-performing circus artists in their

122 later stages of development (see Bloom, 1985). Performers come to the school from around

123 the world and the school is renowned for developing world-class circus artists who desire

124 jobs in premier circus companies, such as Cirque du Soleil (Filho, Aubertin, \& Petiot,

125 2016). This sampling strategy is consistent with the importance of targeting "information-

126 rich cases" in qualitative inquiry (see Patton, 2002). Our choice for this particular circus

127 modality is in agreement with the concept of cognitive team task analysis (see Klein, 2000),

128 which purports that specific working teams can be used as platforms to advance knowledge

129 of team processes. Eight circus acrobats (seven males, one female) from four different

130 dyads participated in the study, including four catchers and four flyers. The participants

131 were 20.87 years old on average $(S D=2.76)$ and had extensive experience in their

132 respective circus domain. Institutional review board ethical approval was obtained prior to 
Running head: TEAM COORDINATION IN HAND-TO-HAND ACROBATICS

133 the commencement of the study. Each participant signed an informed consent sheet after

134 being informed of the purpose, rationale, and methodological procedures for the study.

\section{Data Collection}

136 The leading author, who has experience leading workshops on performance

137 psychology for circus artists, and has published academic manuscripts on expert

138 performance in circus, conducted the data collection. His previous research and applied

139 experience in the circus domain helped to facilitate the opportunity to gather data from

140 high-skilled circus acrobats. To this matter, focus group interviews were the main tool used

141 to gather data on the circus artists' understanding of how TC is developed in dyadic hand-

142 to-hand acts. Focus group interviews were deemed the most appropriate strategy to collect

143 data from the performers as they had rigorous daily schedules, including multiple practices

144 and shows, which limited their availability. To this extent, focus groups have been

145 established as an ideal tool to generate concentrated amounts of data on a topic of interest

146 (Vaughn, Schumm, \& Sinagub, 1996). In addition to two focus group interviews, a peer-

147 debriefing interview with the head coach and a series of naturalist observations were also

148 conducted. This is consistent with the importance of triangulation in qualitative inquiry

149 (Patton, 2002), particularly with the notion that observations and individual interviews can

150 add supplementary information to focus group studies (Bruun et al., 2014; Vaughn et al.,

151 1996; Willig \& Stainton-Rogers, 2007).

152 Focus group interviews. The focus group interviews were conducted under the

153 moderation of the leading author. The first interview involved five performers from three

154 dyads and the second involved eight performers from four different dyads. These numbers

155 are congruent with recent guidelines on qualitative inquiry, which suggest that focus group 
156 interviews should consist of 4-8 interviewees (see Sparkes \& Smith, 2014). To maximize

157 participation in both interviews, the acrobats were seated at a round table and given the

158 opportunity to speak in turns.

159 The first interview lasted approximately 45 minutes and was conducted as an

160 exercise, akin to previous qualitative studies (see Bruun et al., 2014; Simons et al., 2012).

161 Thus, the first interview served as a pilot in the development of a structured interview guide

162 for the ensuing main focus group. The resulting interview guide included two main topics:

163 (a) development of "space-time-action" congruence, and (b) TC breakdown. The second

164 interview lasted approximately 75 minutes. Congruent with the interview guide, the

165 opening interview question was conceived to reflect the conceptual basis of TC; that is

166 "space-time-action" congruence. The specific probe was: "How do you develop team

167 coordination in your dyads? For instance, what do you do as a catcher and as a flyer to be at

168 the right spot, at the right time, and making sure you are doing the right thing?" Each

169 participant was given the opportunity to answer the initial question and was subsequently

170 asked to elaborate on his/her ideas while commenting on other's responses and insights.

171 The follow-up comment and question from the moderator was "I found it interesting to hear

172 your thoughts on team coordination, communication, trust... In this second round I will give

173 you a chance to add whatever you want to add, okay? Let's start from here." Finally, the

174 moderator asked additional follow-up questions (e.g., "One person said, and I noticed while

175 I was watching the shows that one of you calls the trick. So how does that work? How do

176 you decide who calls the trick?”), and allowed all participants to respond as desired.

177 Coach interview. The purpose of the coach interview was to elicit additional

178 information about the core components of action proper to hand-to-hand acrobats. During 
179 this interview the leading author gained clarification on the specific roles of the catcher and

180 flyer in the acrobatic act and gathered further information regarding practices and shows.

181 The interview was tape-recorded, lasted approximately 45 minutes, and was conducted in a

182 meeting room at a time chosen by the coach.

183 Field observations. The leading author conducted six observations as a complete

184 observer (i.e., without taking part in the social setting but literally observing from the

185 audience; see Gold, 1958; Willig \& Stainton-Rogers, 2007) in order to gain a better

186 understanding of the coordination dynamics established by flyers and catchers. To allow

187 maximum variation, the interviews were conducted at varying circumstances. Of the six

188 observations, two occurred during practices and four were conducted during live

189 performance shows (two from a backstage perspective and two from an audience

190 perspective). Each observation lasted approximately 75-90 min. Unstructured reflexive

191 notes were maintained by the leading researcher, as the intention was to study TC from a

192 broad naturalistic observation paradigm rather than subscribe to a controlled observation

193 script (see Willig \& Stainton-Rogers, 2007).

\section{Data Analysis}

195 The focus group interview data was coded using inductive thematic analysis, as our

196 goal was to identify the acrobats understanding of TC in hand-to-hand acrobatics. A

197 deductive approach, through direct content analysis, was employed to analyze the coach

198 interview and observation notes according to the themes previously identified in the focus

199 groups.

200 Inductive thematic analysis. The focus group interview data were analyzed

201 inductively based on Braun and Clarke's (2006) theoretical thematic analysis which 
202 consists of six steps: (1) familiarization with the data, (2) generating initial codes, (3)

203 searching for themes, (4) reviewing themes, (5) defining and naming themes, and (6)

204 producing the report. Accordingly, in the first step of the data analysis, both authors read

205 the transcription of the focus group interviews until they became familiar with the data. The

206 first author then organized the transcription into meaning units of text and subsequently

207 grouped these units into themes and sub-themes. In the fourth step, the last author

208 independently reviewed all meaning units as coded by the first author. Meaning units that

209 needed recoding were identified and discussed until consensus was reached among the

210 authors. The fifth step involved defining names for the themes and identifying quotes

211 capturing the essence of each theme and sub-theme. Finally, the results were presented in

212 the manuscript and described in terms of coherence. A thematic map was generated to

213 visually illustrate the results.

214 Direct content analysis. The data gathered from the coach interview and the

215 reflexive notes were analyzed deductively through direct content analysis. In the present

216 study, the predetermined categories used for the direct categorical analysis consisted of the

217 themes and sub-themes identified from the focus interview data. In this regard, there is a

218 general agreement that direct categorical analysis should be used to complement the main

219 data collected in a given study, thus increasing the overall trustworthiness of the findings

220 (Elo \& Kyngäs, 2008). The coding process followed the steps outlined by Hsieh and

221 Shannon (2005). Initially, the first and last author independently read and re-read the

222 verbatim transcripts of the coach interview and the field notes until they became familiar

223 with the data. Subsequently, they independently searched for meaning units reflecting the

224 pre-defined codes (i.e., themes and sub-themes from the interview data). Lastly, they 
Running head: TEAM COORDINATION IN HAND-TO-HAND ACROBATICS

225 discussed their independent categorization until consensus was reached, and selected quotes

226 to be presented in the manuscript write-up.

\section{Results}

The analysis yielded three higher order themes: team coordination (TC), collective

229 efficacy (CE), and TC-CE linkage. TC and CE emerged as unique team processes

230 underlined by different factors. Moreover, TC and CE seemed to co-evolve, thereby being

231 intrinsically inter-related (i.e., TC-CE linkage). These higher order themes are illustrated in

232 Figure 1 and discussed next.

\section{Team Coordination}

234 Our analysis suggests that TC is a multi-layered process involving four sub-themes:

235 shared mental models, complementary mental models, verbal communication, and non-

236 verbal communication.

237 Shared mental models. To achieve TC, the acrobats developed shared knowledge 238 about team tasks and teammates' actions. To this extent, one of the acrobats noted that over 239 time they learn to "feel" where each other will be within a specific movement:

240 Let's say my flyer is doing a one-armed handstand on my head. I can't see him and we can't really talk and I have to balance him. I found that with time you just "feel" each other. I feel his hand, I feel his weight, and I know where he is going and I just respond to that and try to stay under him. (Catcher-2)

244 Complementary mental models. TC also seems to rely on the partners'

245 idiosyncratic complementary knowledge about team tasks. In this regard, one of the

246 catchers highlighted that over time they learn how to "adjust" to each other's movements: 
Running head: TEAM COORDINATION IN HAND-TO-HAND ACROBATICS

We are standing up and she swings and I throw her and that feeling [of throwing] for me, just by the hands. I don't know how but I can feel when she is biking [leg movements in the air], or giving the kick. Even if she is in the bike, and I can't see her, I can adjust if I feel she is too late or too early and she can feel the same if I miss my swing. (Catcher-4)

Verbal communication. Our results suggested that verbal communication appears

253 to be related to the development of TC, particularly during practice sessions when time

254 pressure is not an issue and partners are able to discuss, together with their coaches, how 255 complex movements should be executed: and when you don't agree. And when you have a really good coach who tells you how it [the trick] is, you have to just accept that and kind of figure out the

I think the only time that it [coordination] ever becomes an issue is if you think the trick is like "this" and they [the catchers] think the trick is like "that", way that it [the trick] works for you. I think the trick works like "this" so when we try it and it always fails, I'm not committing to it because I think you [the catcher] should be here, but in fact I don't really know because I've never done the part. But if you keep good communication the other person can start to understand what you are going through. (Flyer-1)

An excerpt from the interview with the head coach also illustrates the importance of

266 verbal communication in solving coordination problems in difficult acrobatic tricks: 
Running head: TEAM COORDINATION IN HAND-TO-HAND ACROBATICS

[the trick] ... what am I doing wrong or what I can do differently to solve the problem. (Head Coach)

272 mimicry of each other's somatic responses (e.g., breathing), are likely paramount to TC

273 especially under time-pressure situations, such as live shows:

274

275

276

There are very specific cues to signal that you are ready and it's usually nonverbal, and it's very specific timing that you practice. For me, almost every trick he calls, basically when he does this one where he throws a leg, I know he is ready. When he goes like this, and he stops moving, I know he is ready. I don't have to wait for him to say anything. (Flyer-3)

It is all based on breathing and timing and just waiting the exact amount of time, because if one person is pushing a little early or a little late then it's [trick] going to be off. So I keep moving until I find a calmness and then I just kind of stop breathing and then as soon as I become still he knows I am ready. (Flyer-1)

Field notes, documented following the field observations, were congruent with the notion that non-verbal communication is important to develop on-stage coordination:

Sometimes it is like eye coordination: "Okay, I look at you and you tell me if you are ready, when I should go". And sometimes it is on the music beat, and then they [the acrobats] will do some sort of choreography. (Back-Stage Observation 2)

\section{Collective Efficacy}


Running head: TEAM COORDINATION IN HAND-TO-HAND ACROBATICS

Collective efficacy (CE) has been defined as, “a group's shared belief in its conjoint capabilities to organize and execute the courses of action required to produce given levels

293 of attainment" (Bandura, 1997, p. 4). Without a shared belief in each other's abilities,

294 partners would be unable to perform successfully while meeting the specific demands

295 proper to hand-to-hand acrobatics:

When you are throwing the flyer up, you don't really know what is going to happen in the air. It is kind of a thing of faith. They trust that you will catch them but you trust that they are going to know what to do in the air and you will catch them no matter what. (Catcher-1)

The head coach alluded to the notion of CE, albeit in colloquial terms, by

301 mentioning the importance of developing "trust" between the two acrobats: you are giving your body fully to somebody else in a way. But trust is also a big part of taking responsibility for everything. If you are working with somebody else, it is not one person's fault, and this is a misconception that people have. Often they will point the finger at somebody else and say "oh, you're not doing this right, you are not..." It's easy to do that, rather than to say "okay, what can I do differently". So it's important for people to understand. It's like tango. It takes two people. (Head Coach) 
Running head: TEAM COORDINATION IN HAND-TO-HAND ACROBATICS

Self-efficacy. Self-efficacy has been defined as "beliefs in one's capabilities to organize and execute the courses of action required to produce given attainments" (Bandura 1997, p. 3). The self-belief that one could perform his/her part in the hand-to-hand act was an important part in building a shared efficacy belief and in the development of TC: him and then we usually just go for it. (Catcher-2) emerged as related to the development of a collective sense of efficacy. To this extent, a

322 catcher noted, "He is a good acrobat and he knows his body and that gives me confidence."

323 Two flyers respectively stated, "I've started to learn the way to 'just let go' and trust him."

324 and "He trusted me and that helped me to overcome my fear and trust myself."

\section{Team Coordination and Collective Efficacy Linkage} coordination goes bad. If I trust him I won't fall because I am letting him control me. So it goes together. If you trust your partner you are going to be more coordinated. (Flyer-3) 
Running head: TEAM COORDINATION IN HAND-TO-HAND ACROBATICS

Our purpose was to explore circus artists' understanding of how TC is developed in dyadic hand-to-hand acts. This circus modality requires "space-time-action" congruence

337 between a flyer and catcher and, as such, represents an epistemologically valid task to study

338 TC. Our findings suggest that TC is dependent on teammates' knowledge (shared and

339 complementary) and communication dynamics (verbal and non-verbal). Perhaps more

340 importantly, our findings advance research in interactive team tasks by revealing that TC in

341 high-risk acrobatics cannot be reduced to mono-causal explanations. Rather, TC is bounded

342 to reciprocal determinism with collective efficacy, which in turn is reflected by the acrobats

343 self- and others' efficacy. The intricacies of these findings are elaborated upon next.

344 Underlying Factors of Team Coordination

345 Our findings suggest that TC depends on SMM, complementary mental models,

346 verbal communication, and non-verbal communication. These four factors seem to be

347 formative rather than reflective indicators of TC. That is, TC is not merely reflected by

348 these sub-themes but seems to be dependent on them (see Hoyle, 2011 on the difference

349 between reflective and formative indicators). In other words, our interpretation is that

350 without shared and complementary mental models, as well as verbal and non-verbal

351 communication exchanges, TC in circus acrobatic might not occur.

352 In low-risk team tasks, coordination might rely on SMM only. However, in complex

353 team tasks, such as high-risk acrobatics, only shared knowledge is likely not enough to

354 ensure coordination. To this extent, recent research on team cognition in circus suggests

355 that the importance of complementary mental models increases with task difficulty (Filho,

356 Bertollo, Robazza, \& Comani, 2015b). Specifically, Filho et al. (2015b) have noted that

357 juggling dyads in circus tend to show both integrative (shared) and segregative 
Running head: TEAM COORDINATION IN HAND-TO-HAND ACROBATICS

358 (complementary) intra-team psychophysiological patterns. Noteworthy, the argument that

359 complex tasks, such as high-risk acrobatics, require both shared and complementary

360 knowledge resonates beyond psychology. From swarms of bees to packs of wolves, to

361 cooperative human teams, researchers across domains have noted that the success of

362 complex cooperative tasks relies on both communal and specialized division of labor (Bietti

$363 \&$ Sutton, 2015).

364 There is robust evidence indicating that the information-processing capacity of

365 different species is linearly related to their ability to establish complex cooperative social

366 groups (see Dunbar, 2009). Thus, a theoretical understanding of TC should consider both

367 shared and complementary mental models. In practice, fostering the development of shared

368 and complementary affective-cognitive-behavioral states and patterns in teams might

369 enhance organization of labor in complex tasks across disciplines (e.g., music, sports, and

370 military). If teammates hold communal and complementary feelings (affective), thoughts

371 (cognitions), and behavioral patterns, coordination losses in team tasks are less likely to

372 happen (Filho, Gershgoren, Basevitch, Schinke, \& Tenenbaum, 2014; Gershgoren et al.,

373 2016).

374 With respect to communication dynamics, our findings extend previous work in

375 applied psychology (see Eccles \& Tenenbaum, 2004; Gershgoren et al., 2013) by

376 suggesting that verbal communication is essential to the development of pre-process

377 coordination actions (i.e., when time pressure is not an issue; e.g., practices), whereas non-

378 verbal communication is key during in-process coordination actions (e.g., athletic

379 competitions or artistic shows) in high-stake situations. Furthermore, our results support the 
notion that head coaches are essential in facilitating communication exchanges that foster

381 the development of TC in interactive teams (see Hackman \& Wageman, 2005). established through the communication of different types of socio-cognitive knowledge

384 (see Garud, 1997). Acrobats verbalize "know-how" (tacit procedural knowledge) and

385 "know-what" (declarative knowledge) information during practices and shows. However,

386 "know-when" (temporal information) seems to be a tacit corporeal exchange established

387 between the acrobats during live performances. Together, knowing "how to do what and

388 when" might help to explain coordination of high-risk dyadic circus acts. In effect,

389 embodied information exchanges among performance artists in other domains, such as

390 music orchestras and sport teams, have also been found to rely on different types of

391 knowledge (Atik, 1994; Filho et al., 2014).

392 The importance of embodied communication in interactive tasks has been

393 emphasized by different streams of research in psychology, sociology, and anthropology.

394 To this effect, Streeck (2015) has observed that "haptic communication via the torsos, arms

395 and hands (p. 425)" of moving bodies is at the core of in-motion coordination of human

396 bodies. To put it another way, the communication of kinesthetic knowledge seems to be an

397 important "means to the end" of space-time-action synchrony in circus acrobatics. The

398 coordination of joint action in other motor tasks, such as in Aikido, has also partially

399 attributed to moment-by-moment whole body information exchanges (see Lefebvre, 2016).

400 More generally, linguist theorists have noted that in-sync moving bodies suggest in-sync

401 moving minds (McNeill, 2008). Furthermore, shared and complementary thoughts are 
Running head: TEAM COORDINATION IN HAND-TO-HAND ACROBATICS

402 revealed through body gestures, and body gestures are revealing of thoughts (see also 403 McNeill, 1992).

404 It follows that an alternative explanation to our findings is that verbal and non-

405 verbal communication exchanges are part of team members' mental models. Indeed,

406 language (from langue) means shared competence that can be expressed through multiple

407 channels including, but not limited to, kinesthetic non-verbal and spoken verbal means

408 (McNeill, 2008). Overall, the role of communication in shaping TC deserves further

409 attention, as human beings can communicate in novel and infinite ways ("the infinite use of

410 finite means"; see Chomsky, 2014). The limitless capacity of human communication,

411 together with the ever-growing evolution of technology, may continuously alter how

412 communication influences TC in both low- and high-risk team activities.

\section{The Role of Collective Efficacy}

414 In the thematic analysis, self- and other's-efficacy emerged as key factors in the 415 establishment of "we" efficacy beliefs. Self-efficacy, other's-efficacy, and CE seem to be

416 intertwined as confidence in oneself, in one's partner, and in the team are likely conditional

417 on one another. Our findings extend previous research by revealing that interactions

418 between the self and another teammate form the basis of CE in dyadic acrobatics. Put

419 differently, self- and other's-efficacy are likely more important in dyadic teams than in

420 teams with more than two members, wherein "effort" and "preparation" have been found to

421 be major predictors of CE (Short et al., 2005). Indeed, team size has been suggested as a

422 moderator of myriad team processes (for a review see Carron, Eys, \& Burke, 2007),

423 including collective efficacy beliefs (Feltz et al., 2008). Overall, as Bandura (1997) has 
Running head: TEAM COORDINATION IN HAND-TO-HAND ACROBATICS

424 long noted, CE is a task and situation specific construct that changes across domains of 425 human activity.

\section{Team Coordination and Collective Efficacy Linkage}

427 Our findings also suggest that TC is likely inter-related to CE. As such, TC cannot

428 be understood in isolation but rather should be considered in a systematic view, similar to

429 the notion of reciprocal determinism and the many-to-many basis relationship in applied

430 social psychology (see Bandura, 1997; Cacioppo et al., 2007). This finding reinforces the

431 notion that an integrated view of team dynamics can be advanced by examining the unique

432 underlying mechanisms of higher-order team processes, such as TC and CE (Collins \&

433 Durand-Bush, 2015; Filho et al., 2015b). In fact, CE has been described as an emergent

434 state in the sense that it develops through reinforcing dynamic interactions with other team

435 processes, such as TC (Marks, Mathieu, \& Zaccaro, 2001).

436 In light of these findings, we reiterate the importance of advancing a parsimonious

437 nomological network linking inputs, throughputs, and outputs in team dynamics research.

438 In this regard, many theorists have vouched for studies examining the systemic linkage

439 among team processes. More recently, Filho and colleagues (2015b) have noted that team

440 members' mental models and CE are inter-related processes and together influence

441 performance in teams. Accordingly, exploring, through different methodological

442 approaches, how team members' shared and complementary mental models relate to TC

443 and CE could allow for a better understanding of team development, team functioning, and

444 team resilience. Altogether, a parsimonious and systemic view of team dynamics would

445 allow for the development of clear applied guidelines for practitioners. 
Running head: TEAM COORDINATION IN HAND-TO-HAND ACROBATICS

To the practitioner, our findings suggest that systemic interventions targeting team

447 processes simultaneously may be more beneficial than fragmented interventions aimed at

448 solving intra-group conflict (e.g., social cliques), for instance. Interventions targeting both

449 TC and CE, as well as other team processes (e.g., cohesion, leadership), may yield better

450 results, as more confident teams will likely suffer from fewer coordination breakdowns, and

451 better coordination will further enhance CE.

$452 \quad$ Limitations

453 The present study is not without limitations. First, our qualitative inquiry is limited

454 in scope and, thereby, our findings should not be taken as factual "windows to the truth".

455 Rather, our findings represent one of many alternatives to the understanding of TC, its sub-

456 themes, and related team processes. In addition to methodological triangulation, future

457 studies should abide by the idea of "interpretative pluralism" (Coyle, 2010). While

458 methodological triangulation pertains to the use of multiple methods, interpretative

459 pluralism consists of applying numerous analytical outlooks to a given phenomenon

460 (Kincheloe, 2005).

461 Second, our study relied primarily on group interviews. Although focus group

462 interviews are valuable in eliciting a shared understanding of a given phenomenon,

463 individuals that are more vocal tend to participate more than those who are reserved.

464 Although every effort was made to allow for equal participation, individual interviews

465 would likely have allowed for additional data and findings. We were unable to collect

466 additional data in the form of individual interviews with the acrobats, consistent with the

467 understanding that access to high-skilled performers is usually limited. Further qualitative

468 studies, based on a maximum variation sampling strategy and a grounded theory approach, 
469

470

471

472

473

474 potential gender effects on the development of TC, and on the observed TC-CE linkage, are

475

476

477

478

479

480

481

482

483

484

485

486

487

488

489

490

491

might help to advance knowledge on the nature of TC in other acrobatic and sport modalities, and across performers of different skill levels.

Third, given that the majority of our participants were male acrobats, a factor outside of our control, we were unable to qualitatively analyze potential differences in same-gender dyads compared to co-ed dyads. Accordingly, future studies analyzing warranted as previous research suggests that gender moderates team processes and performance in working groups (Carron et al., 2007; Feltz et al., 2008). Studies on diverse gender and ethnographic populations are particularly important in the field of Sport,

Exercise and Performance Psychology, wherein the majority of studies have been on college-aged, Caucasian, male performers (Filho \& Tenenbaum, 2015).

\section{Future Research and Applied Implications}

From a theoretical standpoint, scholars should continue to strive for the

development of an integrated theory of team dynamics, wherein the linkage among TC, CE, cohesion and other team processes (e.g., leadership; motivational climate) is addressed in a parsimonious fashion. To this extent, it might be fruitful to continue studying whether TC and CE coevolve or whether TC leads to $\mathrm{CE}$, or vice versa. More research on a dynamic systems view of TC is also warranted. The emergence of affordances at the team-level of analysis is dependent on the number of degrees of freedom (see Marsh et al., 2009; Silva et al., 2013; Vilar et al., 2012). Dyads are different than larger teams as there is no chance for subgrouping or coalition development. Furthermore, in dyadic circus acrobatics all movements are practiced and rehearsed exhaustively and thus minimal adaptation to the environment is needed. It follows that the role of knowledge (shared and complementary) 
Running head: TEAM COORDINATION IN HAND-TO-HAND ACROBATICS

492 and communication (verbal and non-verbal) in promoting TC may differ in teams with

493 more than two members, as well as in open sports where movements are less rehearsed and

494 predictable in comparison to closed sports, such as acrobatics.

495 From a methodological standpoint, the present findings echo the notion that TC can

496 be measured using different tools (Mohammed et al., 2010). Self-report questionnaires on

497 team cognition, measuring both shared and complementary knowledge, might be useful in

498 advancing knowledge of TC. The degree of similarity (e.g., in-phase coupling) or

499 complementarity (e.g., anti-phase coupling) of physiological responses may also be used as

500 a proxy to understand TC in interactive tasks (Kelso, 2012). Future research should

501 continue to advance this idea by focusing on tasks that allow for the use of position

502 monitoring technology (e.g., GPS, accelerometers) or portable multi-subjects physiological

503 monitoring that can be synchronized in real-time. Furthermore, capturing verbal and non-

504 verbal communication (e.g., verbal, such as voice tone and turn talking; and non-verbal

505 behavior, such as mirroring and mimicry posture) may also yield insight into the

506 understanding of TC. In light of our findings, we highlight the importance of considering

507 the linkage of TC with both "we" (e.g., CE) and "I" factors (e.g., self- and other's-efficacy),

508 and controlling for such effects.

$509 \quad$ From an applied standpoint, our findings suggest that TC can be developed through

510 myriad ways. Practitioners should promote the development of both shared and

511 complementary models of thinking, while promoting communication skills through both

512 verbal and non-verbal channels. SMM and complementary mental models might be

513 achieved through cross-positional training among teammates (e.g., flyers working as

514 catchers, and catchers working as flyers), the development of pre-performance routines, and 
Running head: TEAM COORDINATION IN HAND-TO-HAND ACROBATICS

515 the assignment of unique roles to each team member. Active listening (e.g., direct one's

516 attention to the person communicating) and mindfulness (e.g., defer judgment in decoding

517 the message transmitted) training are possible ways to improve communication in

518 cooperative teams. Finally, boosting teammates' self-efficacy and other's efficacy, through

519 goal-setting and modeling, can help not only in the development of CE but also in the

520 enhancement of TC in dyadic acrobatics. 
Running head: TEAM COORDINATION IN HAND-TO-HAND ACROBATICS

\section{References}

522 Arrow, H., Poole, M. S., Henry, K. B., Wheelan, S., \& Moreland, R. (2004). Time, change, and development: The temporal perspective on groups. Small Group Research, 35,

Atik, Y. (1994). The conductor and the orchestra: Interactive aspects of the leadership process. Leadership \& Organization Development Journal, 15, 22-28.

527 Bandura, A. (1997). Self-efficacy: The exercise of control. New York, NY: W. H. Freeman.

528 Bietti, L. M., \& Sutton, J. (2015). Interacting to remember at multiple timescales:

529 Coordination, collaboration, cooperation and culture in joint remembering.

$530 \quad$ Interaction Studies, 16, 419-450.

531 Bloom, B. S. (Ed). (1985). Developing talent in young people. New York, NY: Ballantine.

532 Braun, V., \& Clarke, V. (2006). Using thematic analysis in psychology. Qualitative

533 Research in Psychology, 3, 77-101. doi:10.1191/1478088706qp063oa

534 Bruun, D. M., Krustrup, P., Hornstrup, T., Uth, J., Brasso, K., Rørth, M., ... \& Midtgaard, J.

535 (2014). "All boys and men can play football”: A qualitative investigation of

536 recreational football in prostate cancer patients. Scandinavian Journal of Medicine 537 \& Science in Sports, 24, 113-121.

538 Cacioppo, J. T., Tassinary, L. G., \& Berntson, G. G. (2007). Psychophysiological science: 539 Interdisciplinary approaches to classic questions about the mind. In J. T. Cacioppo, 540 L. G. Tassinary, \& G. Berntson (Eds.), Handbook of psychophysiology (3rd ed.). $541 \quad$ New York, NY: Cambridge University Press. 
Running head: TEAM COORDINATION IN HAND-TO-HAND ACROBATICS

542 Carron, A. V., Eys, M. A., \& Burke, S. M. (2007). Team cohesion: nature, correlates, and

543 development. In S. Jowette, \& D. Lavallee (Eds.), Social psychology in sport (pp.

544 91e102). Champaign, IL: Human Kinetics.

545 Carron, A. V., \& Spink, K. S. (1993). Team building in an exercise setting. The Sport

$546 \quad$ Psychologist, 7, 8-18.

547 Chomsky, N. (2014). Aspects of the theory of syntax (Vol. 11). Cambridge, MA: M.I.T.

$548 \quad$ Press.

549 Collins, J., \& Durand-Bush, N. (2015). Frameworks of team processes in sport: A critical

550 review with implications for practitioners. International Journal of Human

551 Movement and Sports Sciences, 3, 46-59. doi:10.13189/saj.2015.030304

552 Coyle, A. (2010). Qualitative research and anomalous experience: a call for interpretative 553 pluralism. Qualitative Research in Psychology, 7, 79-83.

$554 \quad$ http://dx.doi.org/10.1080/14780880903304600.

555 DeLong, C., Pathak, N., Erickson, K., Perrino, E., Shim, K., \& Srivastava, J. (2011). Team

556 Skill: modeling team chemistry in online multi-player games. In J. Huang, L. Cao,

557 \& J. Srivastava (Eds.), Advances in knowledge discovery and data mining (pp. 519-

558 531). Berlin, Germany: Springer Berlin Heidelberg.

559 Dunbar, R. I. (2009). The social brain hypothesis and its implications for social evolution.

560 Annals of Human Biology, 36, 562-572. doi:10.1080/03014460902960289

561 Eccles, D. (2010). The coordination of labour in sports teams. International Review of

$562 \quad$ Sport and Exercise Psychology, 3, 154-170. doi:10.1080/1750984X.2010.519400 
Running head: TEAM COORDINATION IN HAND-TO-HAND ACROBATICS

563 Eccles, D. W., \& Tenenbaum, G. (2004). Why an expert team is more than a team of

564 experts: A social-cognitive conceptualization of team coordination and

565 communication in sport. Journal of Sport and Exercise Psychology, 26, 542-560.

566 Elo, S., \& Kyngäs, H. (2008). The qualitative content analysis process. Journal of

$567 \quad$ Advanced Nursing, 62, 107-115.

568 Feltz, D. L., Short, S. E., \& Sullivan, P. J. (2008). Self-efficacy in sport. Champaign, IL:

569 Human Kinetics.

570 Filho, E. (2015). "Team chemistry" through chemistry lenses: Interdisciplinary science or a

571 metaphorical conundrum? Frontiers in Psychology, 6,

572 doi:10.3389/fpsyg.2015.00038

573 Filho, E., Aubertin, P., \& Petiot, B. (2016). The making of expert performers at Cirque du

$574 \quad$ Soleil and the National Circus School: A performance enhancement

$575 \quad$ outlook. Journal of Sport Psychology in Action, 7, 68-79.

576 Filho, E., Bertollo, M., Robazza, C., \& Comani, S. (2015b). The juggling paradigm: A

577 novel social neuroscience approach to identify neuropsychophysiological markers

578 of team mental models. Frontiers in Psychology, 6.

579 Filho, E., Gershgoren, L., Basevitch, I., Schinke, R., \& Tenenbaum, G. (2014). Peer

$580 \quad$ leadership and shared mental models in a college volleyball team: A season long

581 case study. Journal of Clinical Sport Psychology, 8, 184-203.

582 Filho, E., \& Rettig, J. (2016). Intergroup conflict management strategies from a Nobel

583 Peace Laureate: The case of Jose Ramos-Horta. Basic and Applied Social

$584 \quad$ Psychology, 38, 351-361.

585 
Running head: TEAM COORDINATION IN HAND-TO-HAND ACROBATICS

586 Filho, E., \& Tenenbaum, G. (2012). Team mental models in sports: An overview. In R.

587 Schinke (Ed.), Athletic insight's writings in sport psychology. Hauppauge, NY:

$588 \quad$ Nova Science Publishers. Inc.

589 Filho, E., \& Tenenbaum, G. (2015). Sports psychology. Oxford bibliographies. Oxford, $590 \quad$ United Kingdom: Oxford University Press.

591 Filho, E., Tenenbaum, G., \& Yang, Y. (2015a). Cohesion, team mental models, and 592 collective efficacy: Towards an integrated framework of team dynamics in sport. Journal of Sports Sciences, 33, 641-653. doi:10.1080/02640414.2014.957714

594 Garud, R. (1997). On the distinction between know-how, know-what, and know595 why. Advances in Strategic Management, 14, 81-102.

596 Gershgoren, L., Basevitch, I., Filho, E., Gershgoren, A., Brill, Y. S., Schinke, R. J., \& 597 Tenenbaum, G. (2016). Expertise in soccer teams: A thematic inquiry into the role 598 of shared mental models within team chemistry. Psychology of Sport and $599 \quad$ Exercise, 24, 128-139. doi:10.1016/j.psychsport.2015.12.002

600 Gershgoren, L., Filho, E., Tenenbaum, G., \& Schinke, R. J. (2013). Coaching shared mental 601 models in soccer: A longitudinal case study. Journal of Clinical Sport $602 \quad$ Psychology, 7, 293-312.

603 Giske, R., Rodahl, S. E., \& Høigaard, R. (2015). Shared mental task models in elite ice 604 hockey and handball teams: Does it exist and how does the coach intervene to make 605 an impact? Journal of Applied Sport Psychology, 27, 20-34.

606 Gold, R. L. (1958). Roles in sociological field observations. Social Forces, 217-223.

607 Hackman, J. R., \& Wageman, R. (2005). A theory of team coaching. Academy of 608 Management Review, 30, 269-287. 
Running head: TEAM COORDINATION IN HAND-TO-HAND ACROBATICS

609 Hiller, N. J., DeChurch, L. A., Murase, T., \& Doty, D. (2011). Searching for outcomes of 610 leadership: A 25-year review. Journal of Management, 37, 1137-1177. doi:10.1177/ 0149206310393520

612 Hoyle, R. H. (2011). Structural equation modeling for social and personality psychology. 613 Thousands Oaks, CA: Sage Publications.

614 Hsieh, H. F., \& Shannon, S. E. (2005). Three approaches to qualitative content analysis. 615 Qualitative Health Research, 15, 1277-1288.

616 Kelso, J. A. S. (2012). Multistability and metastability: Understanding dynamic 617 coordination in the brain. Philosophical Transactions of the Royal Society B: Biological Sciences, 367, 906-918. doi:10.1098/rstb.2011.0351

619 Kincheloe, J. (2005). On to the next level: continuing the conceptualization of the 620 bricolage. Qualitative Inquiry, 11, 323-350.

621 Klein, G. (2000). Cognitive task analysis of teams. In J. M. Schraagen, S. F. Chipman, \& 622 V. L. Shalin (Eds.), Cognitive task analysis (pp. 417-430). Mahwah, NJ: Lawrence 623 Erlbaum.

624 Klimoski, R., \& Mohammed, S. (1994). Team mental model: Construct or metaphor? 625 Journal of Management, 20, 403-437. doi:10.1016/0149-2063(94)90021-3

626 Lefebvre, A. (2016). The coordination of moves in Aikido interaction. Gesture, 15, 123$627 \quad 155$.

628 Marks, M. A., Mathieu, J. E., \& Zaccaro, S. J. (2001). A temporally based framework and 629 taxonomy of team processes. Academy of Management Review, 26, 356-376. 
Running head: TEAM COORDINATION IN HAND-TO-HAND ACROBATICS

630 Marsh, K. L., Richardson, M. J., \& Schmidt, R. C. (2009). Social connection through joint action and interpersonal coordination. Topics in Cognitive Science, 1, 320-339. doi:10.1111/j.1756-8765.2009.01022.x

633 Mathieu, J. E., Heffner, T. S., Goodwin, G. F., Salas, E., \& Cannon-Bowers, J. (2000). The influence of shared mental models on team process and performance. Journal of Applied Psychology, 85, 273-283. doi:10.1037/0021-9010.85.2.273

McNeill, D. (2008). Gesture and thought. Chicago, IL: The University of Chicago Press.

McNeill, D. (1992). Hand and mind: What gestures reveal about thought. Chicago, IL: The

Ménard, J. F., \& Hallé, M. (2014). Circus also needs performance psychology: Facts and realities of consulting at Cirque du Soleil. In J. G. Cremades \& L. S. Tashman (Eds.), Becoming a sport, exercise, and performance psychology professional: A

643 Mills, J., Bonner, A., \& Francis, K. (2006). Adopting a constructivist approach to grounded 644 theory: Implications for research design. International Journal of Nursing Practice, 12, 8-13.

646 Mohammed, S., Ferzandi, L., \& Hamilton, K. (2010). Metaphor no more: A 15-year review 647 of the team mental model construct. Journal of Management, 36, 876-910. doi:10.1177/0149206309356804

649 Patton, M. Q. (2002). Qualitative research and evaluation methods (3rd ed.). Thousand $650 \quad$ Oaks, CA: Sage Publications.

651 Peterson, E., Mitchell, T. R., Thompson, L., \& Burr, R. (2000). Collective efficacy and 652 aspects of shared mental models as predictors of performance over time in work 
Running head: TEAM COORDINATION IN HAND-TO-HAND ACROBATICS

groups. Group Processes \& Intergroup Relations, 3, 296-316. doi:10.1177/1368430200033005

Reimer, T., Park, E. S., \& Hinsz, V. B. (2006). Shared and coordinated cognition in competitive and dynamic task environments: An information-processing perspective for team sports. International Journal of Sport and Exercise Psychology, 4, 376400. doi:10.1080/1612197X.2006.9671804

Salas, E., Rosen, M. A., Burke, C. S., Goodwin, G. F., \& Fiore, S. (2006). The making of a dream team: When expert teams do best. In K. A. Ericsson, N. Charness, P. J.

Short, S. E., Sullivan, P., \& Feltz, D. L. (2005). Development and preliminary validation of Feltovich \& R. R. Hoffman (Eds.), The Cambridge handbook of expertise and expert performance (pp. 439-453). New York, NY: Cambridge University Press. the collective efficacy questionnaire for sports. Measurement in Physical Education and Exercise Science, 9, 181-202.

Silva, P., Garganta, J., Araújo, D., Davids, K., \& Aguiar, P. (2013). Shared knowledge or

673 Sparkes, A. C., \& Smith, B. (2014). Qualitative research methods in sport, exercise and 674 health: From process to product. New York, NY: Routledge. 
Running head: TEAM COORDINATION IN HAND-TO-HAND ACROBATICS

675 Streeck, J. (2015). Embodiment in human communication. Annual Review of $676 \quad$ Anthropology, 44, 419-438.

677 Vaughn, S., Schumm, J. S., \& Sinagub, J. M. (1996). Focus group interviews in education 678 and psychology. Thousand Oaks, CA: Sage Publications.

679 Vilar, L., Araújo, D., Davids, K., \& Button, C. (2012). The role of ecological dynamics in 680 analysing performance in team sports. Sports Medicine, 42, 1-10.

681 Willig, C., \& Stainton-Rogers, W. (Eds.). (2007). The SAGE handbook of qualitative 682 research in psychology. Thousand Oaks, CA: Sage Publications.

683 Wood, H. (2003). Space-time continuum. Nature Reviews Neuroscience, 4. 684 doi: $10.1038 / \mathrm{nrn} 1110$

685 Xinwen, B., Erping, W., Ying, Z., Dafei, M., \& Jing, R. (2006). Developmental 686 characteristics of two types of shared mental models. Acta Psychologica Sinica, 38, $687 \quad 598$. 
688

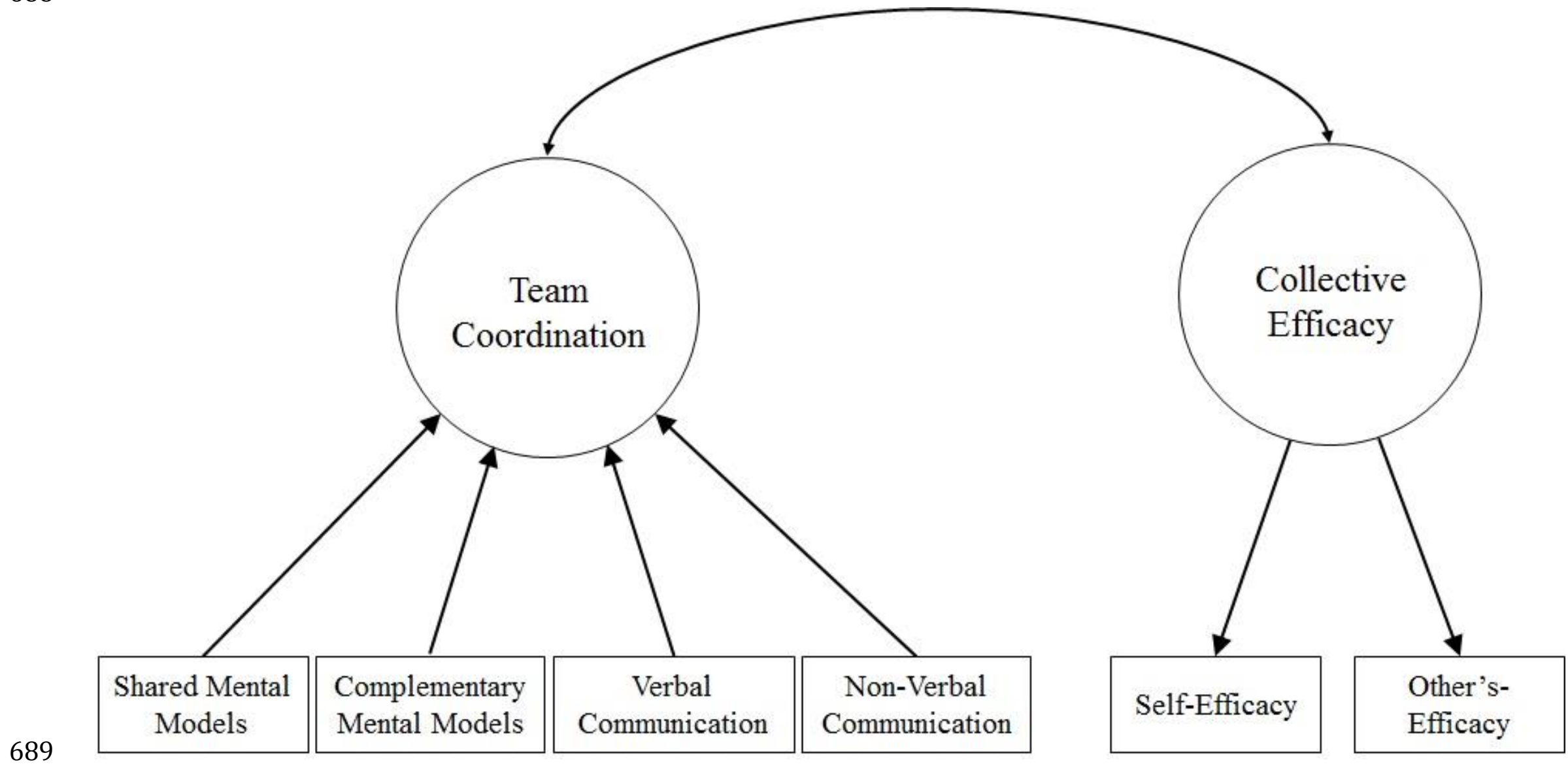

690

Figure 1. Formative Sub-themes of Team Coordination and Reflective Sub-themes of Collective Efficacy. 
Running head: TEAM COORDINATION IN HAND-TO-HAND ACROBATICS

692

693

694

695

696 Circus School.

697

698

699

700

\section{Acknowledgements}

This project was made possible by the support of Cirque du Soleil and the National 